\title{
Preschoolers refer to direct and indirect evidence in their collaborative reasoning
}

DOI:

10.1016/j.jecp.2020.104806

\section{Document Version}

Accepted author manuscript

Link to publication record in Manchester Research Explorer

\section{Citation for published version (APA):}

Köymen, B., Jurkat, S., \& Tomasello, M. (2020). Preschoolers refer to direct and indirect evidence in their collaborative reasoning. Journal of Experimental Child Psychology, 193, [104806].

https://doi.org/10.1016/j.jecp.2020.104806

\section{Published in:}

Journal of Experimental Child Psychology

\section{Citing this paper}

Please note that where the full-text provided on Manchester Research Explorer is the Author Accepted Manuscript or Proof version this may differ from the final Published version. If citing, it is advised that you check and use the publisher's definitive version.

\section{General rights}

Copyright and moral rights for the publications made accessible in the Research Explorer are retained by the authors and/or other copyright owners and it is a condition of accessing publications that users recognise and abide by the legal requirements associated with these rights.

\section{Takedown policy}

If you believe that this document breaches copyright please refer to the University of Manchester's Takedown Procedures [http://man.ac.uk/04Y6Bo] or contact uml.scholarlycommunications@manchester.ac.uk providing relevant details, so we can investigate your claim.

\section{OPEN ACCESS}




\title{
Running Head: DIRECT-INDIRECT EVIDENCE
}

\section{Preschoolers refer to direct and indirect evidence in their collaborative reasoning}

\author{
Bahar Köymen ${ }^{1}$, Solveig Jurkat ${ }^{2}$, Michael Tomasello $^{3-4}$ \\ ${ }^{1}$ University of Manchester \\ ${ }^{2}$ University of Münster \\ ${ }^{3}$ Duke University \\ ${ }^{4}$ Max Planck Institute of Evolutionary Anthropology
}

Corresponding author: Bahar Köymen, Ph.D.

School of Health Sciences, University of Manchester, Oxford Road, Coupland 1 Building M13 9PL, Manchester, United Kingdom.

E-mail: bahar.koymen@manchester.ac.uk,

Telephone: $+44-161-275-2594$

The authors declare no conflict of interest in the publication of this manuscript.

Acknowledgements: We would like to thank Elena Rossi, Claudia Salomo, Anne Tomm, Sinja Thielicke, and Henning Francik for their help with recruitment and data collection; Franziska Zenner for their help with coding; and all daycare centers and children for their friendly cooperation. 


\section{Research Highlights}

- Preschoolers can reason by exclusion in collaborative decision-making.

- Children's reasoning by exclusion gets better when the task has an objectively correct solution than when the task does not have a correct solution.

- Preschoolers "point" to the evidence to justify their proposals.

- 5-year-olds produce indirect reasons more easily than 3-year-olds. 


\begin{abstract}
Collaborative reasoning requires partners to evaluate options and the evidence for/against each option. We investigated whether preschoolers can explain why one option is best (direct reasons) and why the other is not (indirect reasons), looking both at problems that have a correct answer and those that require choosing the better option. In Study 1, both age groups produced direct reasons equally frequently in both problems. But 5-year-olds produced indirect reasons more often than 3-year-olds, especially when there was a correct answer. In Study 2 with a nonverbal task with a correct answer, 3-year-olds produced indirect reasons more often than in Study 1, although 5-year-olds' indirect reasons were more efficiently stated. These results demonstrate that even 3-year-olds, and even nonverbally, can point out to a partner a fact that constitutes a reason for them to arrive at a correct joint decision.
\end{abstract}




\section{Preschoolers refer to direct and indirect evidence in their collaborative reasoning}

A key skill in collaborative problem solving is formulating reasons, and communicating them to one's partner, about a suggested course of action. In fact, recent research on reasoning has emphasized the social dimensions of the process (Mercier \& Sperber, 2011): individuals use reasons to justify to partners why they believe one thing versus another, all in pursuit of the best joint decision (Tomasello, 2019).

Most research on the development of children's collaborative reasoning skills has focused on their comprehension of good versus bad reasons. For example, Koenig (2012) presented preschoolers with two informants with conflicting beliefs about the contents of a box. One supported her conclusion with a valid reason (e.g., "I looked and I saw an apple in the box."); the other with an invalid reason (e.g., "I like apples. I want there to be apples in the box."). Children were able to correctly infer the content of the box (see also Castelain, Bernard, \& Mercier, 2018; Corriveau \& Kurkul, 2014; Mercier, Bernard, \& Clément, 2014).

Recently young children's production of reasons has been investigated particularly in the context of collaborative problem-solving. Three-year-olds were able to recognize when they needed to give reasons: when their partner was ignorant (Baer \& Friedman, 2018; Köymen, Mammen, \& Tomasello, 2016). Köymen, Rosenbaum, and Tomasello (2014) had pairs of 3- and 5-year-old peers decide together where to place toy animals in a zoo. 3-year-olds were skillful at providing relevant reasons. For instance, to justify where to place a penguin, they stated, "because there is ice". Domberg, Köymen, and Tomasello (2018) presented pairs of 5- and 7-year-old peers with a more challenging 
task. The task was more challenging because for the penguin, for instance, the dyads had to choose one of two places that both had ice. Thus, simply pointing out a fact about the physical environment (where the ice is) was not sufficient; pointing out the limitations of the other option(s) was required. Thus, in this study, the 7-year-old children sometimes produced reasons that argued against one of the two options and referred to indirect evidence, so-called "indirect reasons", leaving the other as the best alternative by default (sometimes called reasoning by exclusion), such as "[The penguin should go here because] It is too crowded there [: the other option]". Five-year-olds relied mostly on "direct reasons" and referred to direct evidence, explaining why one option is better. They used indirect reasons much less often (see Felton \& Kuhn, 2001 for adolescents).

Young children's production of indirect reasons to justify their proposals has thus been studied only using the more difficult task in which there was no correct option only better and worse options based on a comparison of evaluative judgments. It is therefore not clear whether the infrequent use of indirect reasons by young children is due to the difficulty of producing indirect reasons (e.g., holding conflicting perspectives simultaneously in mind and reasoning by exclusion) or due to the kinds of tasks used (e.g., tasks without an objectively correct answer or tasks without any salient reason against one option). Tasks with an objectively correct answer are perhaps easier for young children, because they can simply refer to observable "facts" in the form of direct or indirect reasons to back up their claims. It is well documented that around age 3 , children's social cognition, particularly their reasoning, is dominated by the "objective perspective" (Tomasello, 2019). For instance, in false belief tasks, 3-year-olds systematically indicate that a person with a false belief would still act in accordance with 
reality (the "objective" truth) and have a hard time representing two [subjective] perspectives simultaneously (Perner \& Roessler, 2012; Wellman, Cross, \& Watson, 2001). It is also around age 3 that children show sensitivity to objective "rights" and "wrongs" and justify their moral judgments through normative statements such as "It belongs there" (Köymen, et al., 2014; Rakoczy, Warneken, \& Tomasello, 2008).

In the current two studies, we investigated how 3- and 5-year-old children used direct and indirect reasons to convince their partners. In Study 1, we investigated whether the presence of an objectively correct answer to a task influences children's production of these reasons spontaneously in their peer conversations. We asked 3 and 5-year-old peer dyads to place a toy animal (e.g., a polar bear) in a toy zoo, as children this age would be familiar with a zoo set-up (Köymen, et al., 2014). In the correct-answer condition, there was one obviously correct option (e.g., an ice landscape) and one incorrect option (e.g., a savannah landscape). In the better-answer condition, both options were equally plausible (e.g., each option had an ice landscape, though they differed in other ways). We predicted that both age groups would mostly rely on direct reasons (e.g., "There is ice") in both conditions (Domberg et al., 2018; Mercier, 2011). However, they might rely on indirect reasons more often in the correct-answer condition because it is easier to point out the incorrect alternative in the correct-answer condition (e.g., "That is too hot for polar bears") than in the better-answer condition. We predicted that 5-year-olds would produce indirect reasons more often than 3-year-olds, as 5-year-olds would be better at considering the two conflicting perspectives simultaneously (e.g., favoring one perspective by explaining why the other is not good).

In Study 2, we focused on the correct-answer condition using a simpler 
(potentially nonverbal) task. We made the evidence for and against each option more salient and made the production of indirect reasons less linguistically demanding. We predicted that both 3-and 5-year-olds would be able to produce indirect reasons, although 5-year-olds would produce indirect reasons more efficiently than would 3-year-olds.

\section{Study 1}

Method

\section{Participants}

Seventy-two 3-year-olds $(M=3 ; 8$ Range $=3 ; 5-3 ; 11,36$ girls $)$ and 72 5-yearolds $(M=5 ; 8$, Range $=5 ; 5-5 ; 11,36$ girls $)$ in 72 same-age and same-sex dyads participated in the study. The sample size was determined prior to data collection and was based on prior studies with similar design (e.g., Köymen et al., 2016). An additional six dyads could not be included in the analyses because they did not complete the task (three dyads) or the videos were accidentally deleted (three dyads). Children were native speakers of German and had various socio-economic backgrounds.

\section{Materials}

In each trial (two warm-up trials and three experimental trials), children had to place a toy in one of the two homes, each of which had a background picture. In warm-up trial 1, a toilet had to be placed in a bathroom or a living room. In warm-up trial 2, a fridge had to be placed in a kitchen or a bedroom.

The experimental trial with a polar bear: In the better-answer condition, both options had ice backgrounds. Each option had two relevant objects in the foreground (fish 
and igloo in one; meat and ice-cave in the other). In the correct-answer condition, one option had an ice background with all of the four relevant objects; the other a savannah background without any objects in the foreground. We avoided to put any irrelevant objects in the foreground of the incorrect option to avoid confusion and distraction in children.

The experimental trial with a horse: In the better-answer condition, both options had meadow backgrounds. Each option had two relevant objects in the foreground (a carrot and a saddle in one; a brush and an apple in the other). In the correct-answer condition, one option had a meadow background with all of the four relevant objects; the other a desert background without any objects in the foreground.

The experimental trial with a bird: In the better-answer condition, both options had forest backgrounds. Each option had two relevant objects in the foreground (a nest and seeds in one; a birdhouse and a worm in the other). In the correct-answer condition, one option had a forest background with all of the four relevant objects; the other an ocean background without any objects in the foreground.

\section{Procedure}

The procedure of this study is approved by the Research Ethics Committee of $\mathrm{X}$ (Project title: "Collaborative reasoning"). The study took place in quiet rooms of the nurseries. In warm-up trial 1, the experimenter (E) asked children to name the two rooms, the bathroom and the living room. E, then, pointed at the sealed box with the toilet, and said, "You two will decide together to which room the toilet should go" and then asked why after children chose the correct option to prime children to provide reasons for their 
decisions. Children often said, "Because that is the bathroom". Then E repeated the procedure for the warm-up trial 2 with the fridge.

In the experimental trials, E said, "Here is a stack of three puzzles (see Figure 1 for the set-up). Start with the top one, then the middle one and finally the bottom one. In each of these three boxes, there is an animal. For each animal, you two need to decide together which of the two homes is better and explain why. If you find the better homes, you both will get a big surprise gift!” E, then, left the room until children were done. The only difference between the conditions was the background pictures of the two homes for each animal. In the better-answer condition, each home had an appropriate background (see the materials section). In the correct-answer condition, one home had the appropriate background; the other did not. The side of the homes (left vs. right) and the order of the target animals were counterbalanced. The whole procedure lasted about 10-15 minutes.

\section{Coding}

Children's conversations with their peer partner were transcribed, each line corresponding to a clause. We identified lines with reasons and coded each reason for its type:

- Direct reasons explaining why an animal should go to a home (e.g., "There is ice").

- Indirect reasons explaining why an animal should not go to a home (e.g., "It will drown there").

A second coder, blind to the hypotheses and conditions, re-coded $22 \%$ of the transcripts (16 dyads: four in each age and condition). The agreement for the identification of reasons and their type were $\kappa=.81$, and $\kappa=.80$ respectively. 


\section{Results}

In the correct-answer condition, children in both age groups predominantly chose the correct home in the correct-answer condition ( $90 \%$ of the trials). In the better-answer condition, children's preferences for each option were $42 \%$ vs. $58 \%$ for the polar bear, $19 \%$ vs. $81 \%$ for the bird, $17 \%$ vs. $83 \%$ for the horse (Appendix shows for the breakdown of the choices in the two age groups). Thus, for the bird and the horse, both age groups showed a preference for one option over the other in the better-answer condition.

First, we analyzed whether the frequency of children's reasons varied between age groups and conditions. Children produced a total of 318 reasons (four dyads did not produce any reasons, see Figure 2 for the mean number of reasons across age groups and conditions). We used a generalized linear mixed model (GLMM) with poisson error distribution because GLMM allowed us to analyze the frequency of reasons, whilst controlling for the total number of utterances (number of lines in the transcript) produced by each dyad with an offset term. The unit of analysis was each dyad $(N=72)$. The response variable was the number of reasons that each dyad produced. The full model included age group $(3,5)$, condition (correct-answer, better-answer) and their interaction, gender, and the offset term of the number of utterances (log-transformed). The null model included gender and the offset term. The full model improved the fit as compared to the null model $\left(\chi^{2}=31.83, d f=3, p<.001\right)$. However, the interaction between age and condition was not significant $\left(\chi^{2}=0.58, d f=1, p=.446\right)$, so we dropped this interaction term. The reduced model revealed only a significant age difference $\left(\chi^{2}=28.89, d f=1\right.$, 
$p<.001$; Figure 2): 5-year-olds produced reasons more often than did 3-year-olds. There was no significant condition difference $\left(\chi^{2}=0.73, d f=1, p=.392\right)$.

Next, we analyzed direct and indirect reasons and whether their frequency varied between age groups and conditions, using GLMM with poisson error distribution. The offset term was the total number of reasons. In the first analysis, the unit of analysis was each dyad $(N=68$, four dyads who did not produce reasons were excluded from this analysis). The response variable was the number of direct reasons. The full model included age group $(3,5)$, condition (correct-answer, better-answer) and their interaction, gender, offset term of the total number of reasons (log-transformed). The null model included only gender and the offset term. The full model did not improve the fit as compared to the null model $\left(\chi^{2}=2.98, d f=3, p=.394\right)$, suggesting that the frequency of direct reasons did not differ significantly across age groups or conditions (Figure 3). In the second analysis, the response variable was the number of indirect reasons. The full and the null models were the same as the previous analysis. The full model improved the fit as compared to the null model $\left(\chi^{2}=29.35, d f=3, p<.001\right)$. The interaction between age and condition was significant $\left(\chi^{2}=4.58, d f=1, p=.032\right)$ : 5-year-olds produced indirect reasons more than did 3-year-olds (who produced almost none) in both conditions, but the difference was greater in the correct-answer condition.

\section{Discussion}

In this study 5-year-olds produced more reasons that did 3-year-olds in both conditions. Both age groups predominantly used direct reasons in both conditions. Fiveyear-olds produced indirect reasons more often than did 3-year-olds, especially in the 
correct-answer condition. Children's knowledge about the animals and their habitats is unlikely to explain this age difference because this age difference was observed only with indirect reasons and not with direct reasons. Nonetheless, children overall did not produce indirect reasons very frequently in their spontaneous peer interactions, in line with the findings of Domberg and colleagues (2018); 3-year-olds produced almost none at all.

In the correct-answer condition, one option was obviously correct, whereas in the better-answer condition, either option was fine so children's proposals were rarely challenged, though children could still provide indirect reasons against their less favorite option (e.g., "There is too little grass there [for the horse]"; "The igloo is for penguins [not for polar bears]"). This agreement might have reduced the frequency of the reasons, especially the indirect reasons. Therefore, in Study 2, we focused more closely on the correct-answer condition and simplified the task. First, we gave children an adult partner who acted unsure and asked children to justify their decisions. Second, we also increased the saliency of the evidence for/against each option and reduced the linguistic demands of the task such that simply pointing at the evidence would be enough to justify one's proposal. A recent study by Mascaro, Aguirre, Brun, Couderc, and Mercier (2019) have used a nonverbal task and found that when their claims are challenged by an adult, e.g., "no the dog is not there", 2- to 4-year-olds were able to correct the adult by pointing to where the dog actually is.

\section{Study 2}


In Study 2, we exposed children to a clean toy and a toy that leaves traces (e.g., has paint on its feet). Each toy was then hidden in one of two houses and one house had traces in front of it. In the direct-evidence condition, the child together with an adult partner was asked to identify the house containing the toy that left traces; in the indirectevidence condition, the house containing the clean toy. In both conditions, simply pointing at traces would be sufficient to justify a location. However, the pointing would be a direct reason in the direct-evidence condition (indicating where the sought-after toy is); an indirect reason in the indirect-evidence condition (indicating where the soughtafter toy is not). We predicted that both age groups would refer to the traces in both conditions, producing direct reasons in the direct-evidence condition and indirect reasons in the indirect-evidence condition. We also predicted that in the indirect-evidence condition, 5-year-olds would be more efficient in their indirect reasons and rely on less informative reasons or simple reasons such as pointing at the traces; whereas 3-year-olds might produce more informative or more elaborate indirect reasons (e.g., "This is the doll's traces, so the car is in that house), as the sensitivity to over-informative utterances emerge around age 5. That is, 5-year-olds, unlike 3-year-olds, start rejecting “overinformative" utterances or get confused by over-informative utterances (see Davies \& Katsos, 2010; Morriseau, Davies \& Matthews, 2013).

\section{Method}

\section{Participants}

Forty-eight 3-year-olds $(M=3 ; 10$, Range $=3 ; 6-4 ; 0,24$ girls $)$ and 48 5-year-olds $(M=5 ; 10$, Range $=5 ; 8-5 ; 10,24$ girls $)$ participated in the study. The sample size was determined prior to data collection based on prior studies with similar design/analyses 
(e.g., Misch, Over, \& Carpenter, 2016). An additional 20 3-year-olds (7 in the directevidence condition, 13 in the indirect-evidence condition) and two 5-year-olds (one in each condition) were excluded from analyses because they incorrectly answered the question about the location of the toy. Children were native speakers of German and had various socio-economic backgrounds.

\section{Materials}

We used a doll and a car hidden in two houses.

\section{Procedure}

The procedure of this study is approved by the Research Ethics Committee of $\mathrm{X}$ (Project title: "Collaborative reasoning"). The study took place in our laboratory. The child and the two experimenters (E1 and E2) first played with a puppet for familiarization. E1 pointed out that there are two houses in the room and then introduced the two toys: the doll and the car. The first toy (counterbalanced which toy) was introduced as the "clean toy". E1 moved the clean toy on a piece of paper and said, "All clean!". E1 then introduced the toy that leaves traces: "Look this is the doll/car that loves paint [E1 dipped the feet/wheels in paint]". She moved the toy on a piece of paper and pointed out: "Look at the traces!". E2 suggested to play a game and said "I will hide the doll in one house and the car in the other house. You two will find out in which house X is". In the direct-evidence condition, $\mathrm{X}$ was the toy that left traces. In the indirectevidence condition, $\mathrm{X}$ was the clean toy. After E2 hid the toys, one house had traces leading to it (Figure 4). Therefore, in the direct-evidence condition, the traces indicated 
where the sought-after toy was; whereas in the indirect-evidence condition, the traces indicated where the sought-after toy was not.

E1 and the child sat side-by side facing the two houses behind a barrier. E1 said, "In which house is the X?" and waited for the child to point at a house. E1 repeated this question until the child picks a house. Then E1 asked three why-questions: "How do you know it is there?"; "How did you figure out that it is there?"; "It is there because ...?" If the children produced a reason after a question, E1 did not ask more questions. If children answered the question about the location of the toy incorrectly and never revised their answer during why-questions, these children were excluded from the analyses. The toy that left traces and the location of traces (left vs. right) were counterbalanced.

\section{Coding}

We coded each child's reason with the following categories:

1) Simple reasons: pointing at traces with/without minimal verbal explanations with the following four subcategories:

- Direct reasons with reference to the:

○ traces (pointing, "because of the traces")

○ clean path ("because it is clean")

- Indirect reasons with reference to the:

- traces (pointing, "because of the traces")

○ clean path ("because it is clean")

2) Elaborate reasons: identifying the toy or giving extra information with the following two subcategories: 
- Direct reasons (e.g., "There are the doll's traces [so there is the doll]")

- Indirect reasons (e.g., "There are the doll's traces [so there is the car]")

\section{3) Irrelevant/no reasons ("I heard it")}

It should be noted that same reasons were coded as direct or indirect depending on the proposal they justified. Some children spontaneously justified their choices before the why-questions. E1 asked these children the why-questions again and we included the more elaborate reason of the two in the analyses. A second coder re-coded the $25 \%$ of the type of children's reasons (24 children, 6 in each age group and condition). The agreement was $\kappa=1.00$.

\section{Results}

In response to the question "In which house is the X?", 84 children out of 96 (87.5\%) gave a correct response; 12 children (12.5\%) initially gave an incorrect response but revised their answer after being asked why. 79 out of 96 (82\%) children provided a relevant reason for their proposals.

First, we compared the two age groups in each condition in terms of the number of children who produced a relevant reason. In the direct-evidence condition, there was no significant difference between the number of 3-and 5-year-olds who produced a relevant reason $\left(\chi^{2}(1, N=48)=0.19, p=.663\right)$. In the indirect-evidence condition, the number of 5-year-olds who produced a relevant reason was significantly higher than that of 3-year-olds $\left(\chi^{2}(1, N=48)=4.25, p=.039\right.$; Figure 5).

Next, we focused on the indirect reasons and whether the number of children who produced indirect reasons varied depending on age and condition. In each age group, the 
number of children who used an indirect reason was significantly higher in the indirectevidence condition than in the direct-evidence condition (3-year-olds: $\left(\chi^{2}(1, N=35)=\right.$ 13.17, $p<.001)$; 5-year-olds: $\left(\chi^{2}(1, N=44)=21.15, p<.001\right)$; Figure 6). There was no significant difference between the number of 3- and 5-year-olds who produced an indirect reason in the indirect-evidence condition $\left(\chi^{2}(1, N=37)=0.58, p=.446\right)$. That is, both age groups predominantly relied on direct reasons in the direct-evidence condition and indirect reasons in the indirect-evidence condition.

Finally, we compared whether the number of children who produced elaborate reasons varied depending on age and type of reasons (direct reason vs. indirect reason). Because children almost never used indirect reasons in the direct-evidence condition (Figure 6), we did not look at whether children's use of elaborate reasons varied across conditions. There was no significant difference between the number of 3- and 5-year-olds who produced an elaborate direct reason $\left(\chi^{2}(1, N=52)=1.69, p=.193\right)$; both age groups mostly used simple direct reasons (Figure 7). However, the number of 3-year-olds who produced an elaborate indirect reason was significantly higher than that of 5-yearolds $\left(\chi^{2}(1, N=27)=4.69, p=.030\right)$.

\section{Discussion}

In this simplified task, children were able to produce indirect reasons, more frequently than they did in Study 1. In the direct-evidence condition, 3- and 5-year-olds were very similar: both age groups provided simple reasons at equal rates, mostly by pointing at the traces. In the indirect-evidence condition, however, 3-year-olds had a harder time with the task, as evidenced by the high rates of drop-outs (two thirds of the 3- 
year-old dropouts were in the indirect-evidence condition; see also Mascaro et al., 2019 who also found reduced accuracy without adult scaffolding in a similar task). Moreover, 3-year-olds provided a reason in the indirect-evidence condition less often than did 5year-olds. The pattern of 3-year-olds might be explained by the difficulty of cognitively representing two conflicting perspectives (see Wellman et al., 2001).

Although there was no significant age difference in the frequency of indirect reasons, 3-year-olds produced more elaborate indirect reasons than did 5-year-olds. This finding that children were over-informative stands in contrast with studies showing that preschoolers can produce statements that are often optimally informative (Köymen et al., 2014; 2016) or under-informative (Matthews, et al., 2007). Nonetheless, the more elaborate indirect reasons produced by the 3-year-olds in our study can be explained by their difficulty in referring to indirect evidence. As evidenced by both studies, producing indirect reasons required less effort for 5-year-olds who could judge the minimal amount of information necessary to communicate their reasons.

Overall, these findings are in line with those by Mascaro and colleagues (2019) who found that nonverbal tasks facilitate young children's reason-giving. But children's reason-giving in their study was limited to direct reasons: children actually showed the adult where a toy was (turned around a box) to support their claim. Our findings go beyond this by demonstrating that children are able to communicate indirect reasons, that is, not by showing or pointing to a toy's location but rather by indicating the evidence (the traces) for believing the toy to be in one location rather than another. 


\section{General Discussion}

In two studies, we found that when referring to direct evidence, 3- and 5-year-old children reason in very similar ways with their partners. However, by age 5 , and only in simplified situations at age 3 , when children are able to cognitively represent two conflicting perspectives, they are able to refer to indirect evidence (indirect reasons) for their proposals by explaining why an alternative is incorrect. Particularly simplified nonverbal tasks, in which the evidence for/against an option was salient, facilitated the production of indirect reasons by preschool children. In contexts of collaborative problem-solving, where partners justify their beliefs to one another, especially when the linguistic demands are minimized, young children display sophisticated reasoning skills (e.g., reasoning by exclusion) that nevertheless develop significantly across the preschool years. 


\section{References}

Baer, V. \& Friedman, O. (2017). Fitting the message to the listener: Children selectively mention general and specific facts. Child Development, 89, 461-475. doi:10.1111/cdev.12751

Castelain, T., Bernard, S. \& Mercier, H. (2018). Evidence that two-year-old children are sensitive to information presented in arguments. Infancy, 23, 124-135. doi: 10.1111/infa. 12202

Corriveau, K. H. \& Kurkul, K. E. (2014). "Why does rain fall?”: Children prefer to learn from an informant who uses noncircular explanations. Child Development, 85 , 1827-1835. doi:10.1111/cdev.12240

Davies, C. \& Katsos, N. (2010). Over-informative children: Production/comprehension asymmetry or tolerance to pragmatic violations?. Lingua, 120(8), 1956-1972. https://doi.org/10.1016/j.lingua.2010.02.005

Domberg, A., Köymen, B., \& Tomasello, M. (2018). Children's reasoning with peers in cooperative and competitive contexts. British Journal of Developmental Psychology, 36, 64-77. doi:10.1111/bjdp.12213

Felton, M., \& Kuhn, D. (2001). The development of argumentive discourse skill. Discourse Processes, 32(2-3), 135-153. doi:10.1080/0163853X.2001.9651595

Koenig, M. A. (2012). Beyond semantic accuracy: Preschoolers evaluate a speaker's reasons. Child Development, 83, 1051-1063. doi:10.1111/j.14678624.2012.01742.x 
Köymen, B., Lieven, E., Engemann, D. A., Rakoczy, H., Warneken, F., \& Tomasello, M. (2014). Children's norm enforcement in their interactions with peers. Child Development, 85, 1108-1122. doi:10.1111/cdev.12178

Köymen, B., Mammen, M., \& Tomasello, M. (2016). Preschoolers use common ground in their justificatory reasoning with peers. Developmental Psychology, 52, 423429. doi:10. 1037/dev0000089

Köymen, B., Rosenbaum, L., \& Tomasello, M. (2014). Reasoning during joint decisionmaking by preschool peers. Cognitive Development, 32, 74-85. doi:10.1016/j.cogdev.2014. 09.001

Mascaro, O., Aguirre, M., Brun, M., Couderc, A., \& Mercier, H. (2019, July 8). Nonverbal rhetoric: 2- to 4-year-old children select relevant evidence when trying to influence others. Developmental Psychology. Advance online publication. doi:10.1037/dev0000779

Matthews, D., Lieven, E., \& Tomasello, M. (2007). How toddlers and preschoolers learn to uniquely identify referents for others: a training study. Child Development, 78(6), 1744-1759. doi:10.1111/j.1467-8624.2007.01098.x

Mercier, H. (2011). Reasoning serves argumentation in children. Cognitive Development, 26, 166-191. doi: 10.1016/j.cogdev.2010.12.001

Mercier, H., Bernard, S., \& Clément, F. (2014). Early sensitivity to arguments: How preschoolers weight circular arguments. Journal of Experimental Child Psychology, 125, 102-109. doi:10.1016/j.jecp.2013.11.011

Mercier, H. \& Sperber, D. (2011). Why do humans reason? Arguments for an argumentative theory. Behavioral and Brain Sciences, 34, 57-74. 
doi:10.1017/S0140525X10000968

Misch, A., Over, H., \& Carpenter, M. (2016). I won't tell: Young children show loyalty to their group by keeping group secrets. Journal of Experimental Child Psychology, 142, 96-106. doi: 10.1016/j.jecp.2015.09.016

Morisseau T., Davies, C., \& Matthews, D. (2013). How do 3- and 5-year-olds respond to under- and over-informative utterances? Journal of Pragmatics, 59, 26-39. doi:10.1016/j.pragma.2013.03.007

Perner, J., \& Roessler, J. (2012). From infants' to children's appreciation of belief. Trends in Cognitive Sciences, 16, 519-525. doi:10.1016/j.tics.2012.08.004

Rakoczy, H., Warneken, F., \& Tomasello, M. (2008). The sources of normativity: Young children's awareness of the normative structure of games. Developmental Psychology, 44, 875-881. doi:10.1037/0012-1649.44.3.875

Tomasello, M. (2019). Becoming Human: A Theory of Ontogeny. Cambridge, MA: Harvard University Press.

Wellman, H. M., Cross, D., \& Watson, J. (2001). Meta- analysis of theory-of-mind development: The truth about false belief. Child Development, 72(3), 655-684. doi:10.1111/1467-8624.00304 
Figure 1. The set-up of Study 1.

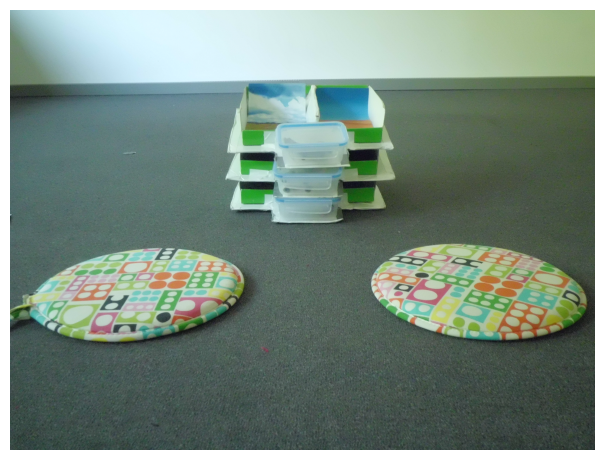


Figure 2. Mean number of reasons that 3- and 5-year-old dyads produced in each condition.

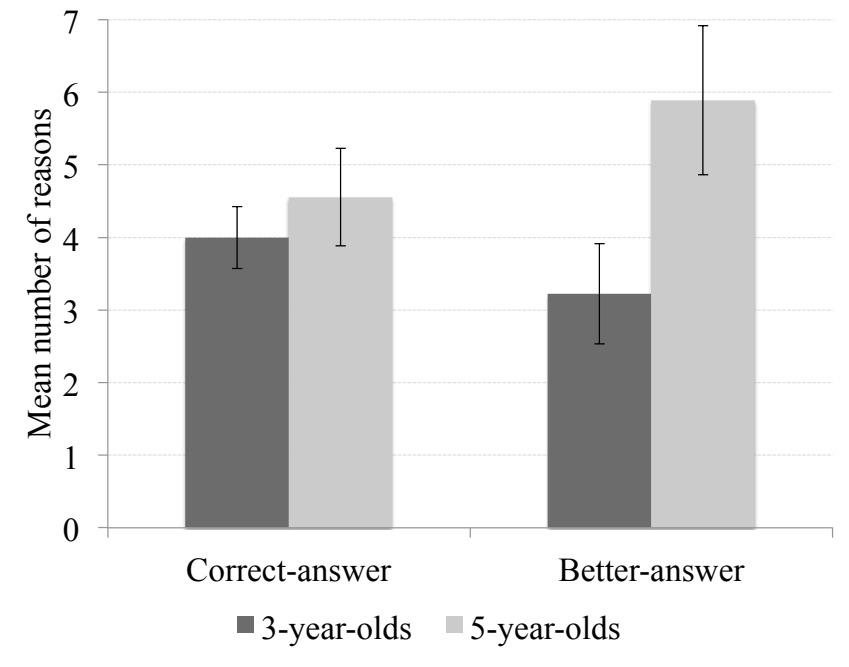


Figure 3. Mean proportion of direct and indirect reasons.

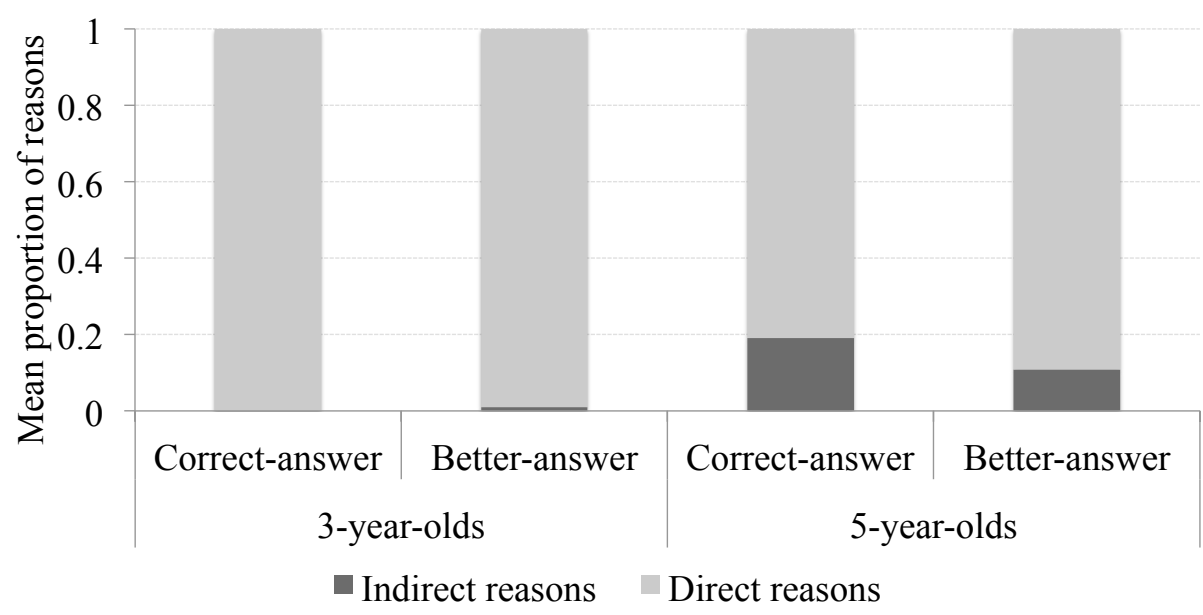


Figure 4. The houses from the perspective of the child and E1.

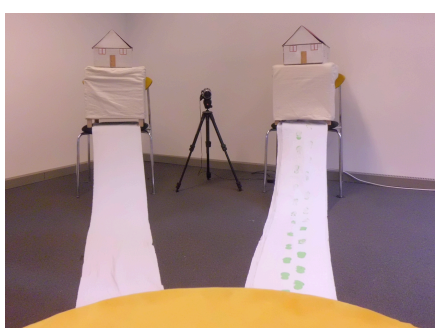


Figure 5. The proportion of children who produced a relevant reason in each condition.

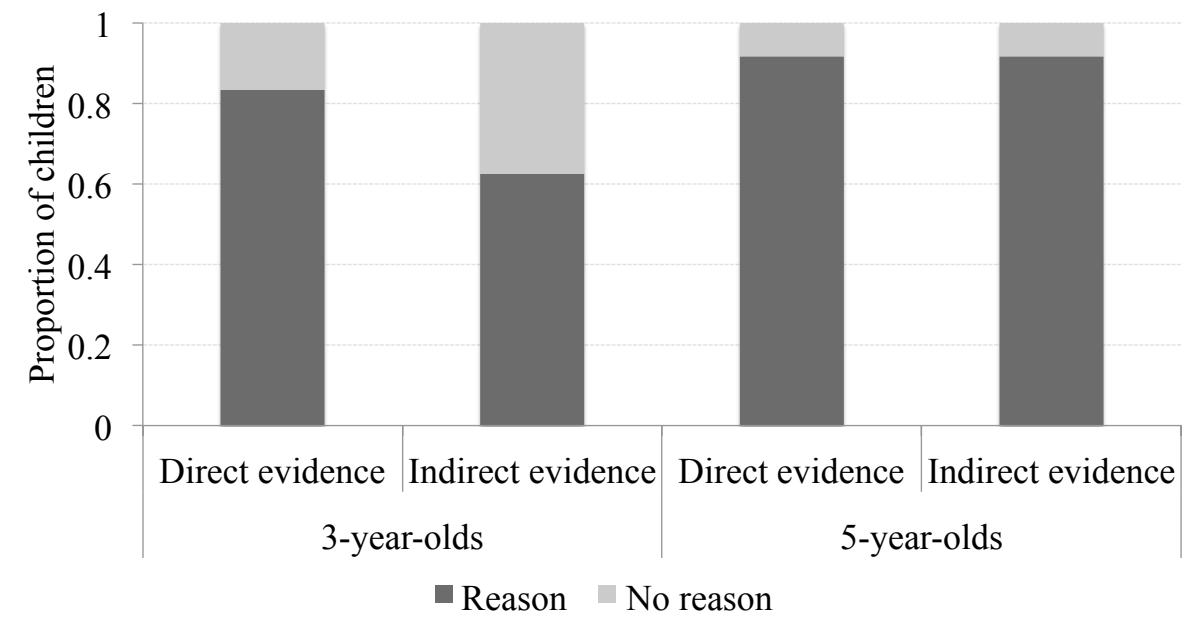


Figure 6. The proportion of children who produced an indirect reason in each age group and condition.

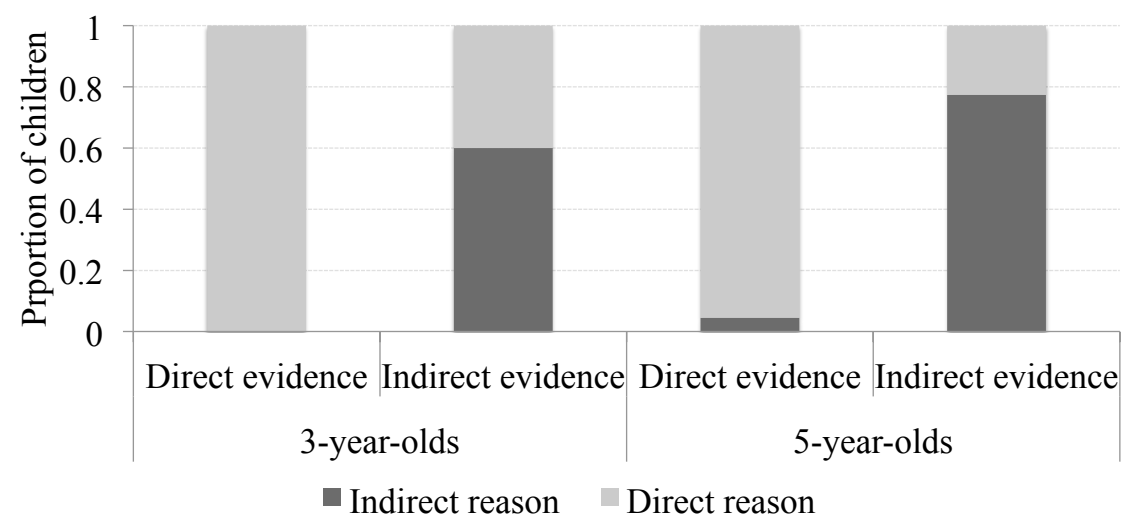


Figure 7. The proportion of children who produced a simple/elaborate direct/indirect reason.

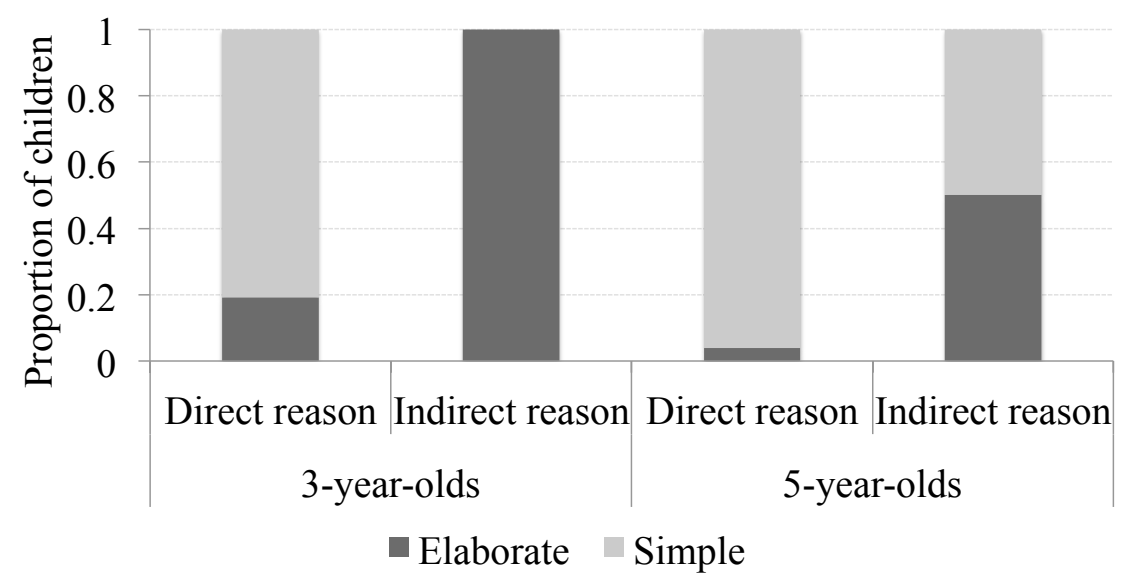


Appendix. The percentage of dyads that chose each option (the number of dyads). In the better answer condition, for the bird, Option 1 had the birdhouse and the earthworm; Option 2 had the nest and the seeds. For the horse, Option 1 had the brush and the apple; Option 2 was the saddle and the carrot. For the polar bear, Option 1 was the fish and the igloo; Option 2 was the cave and the meat.

\section{Correct Answer Condition}

\begin{tabular}{|c|c|c|c|c|}
\hline \multirow[b]{3}{*}{ Polar Bear } & \multicolumn{2}{|c|}{ 3-year-olds } & \multicolumn{2}{|c|}{ 5-year-olds } \\
\hline & Correct & Incorrect & Correct & Incorrect \\
\hline & $94 \%(17)$ & $6 \%(1)$ & $100 \%(18)$ & $0 \%(0)$ \\
\hline Horse & $83 \%(15)$ & $17 \%(3)$ & $100 \%(18)$ & $0 \%(0)$ \\
\hline Bird & $72 \%(13)$ & $28 \%(5)$ & $89 \%(16)$ & $11 \%(2)$ \\
\hline
\end{tabular}

Better Answer Condition

3-year-olds

Option 1 Option

Polar Bear 50\%(9) 50\%(9)

Horse $\quad 11 \%(2) \quad 89 \%(16)$

Bird 28\%(5) 72\%(13) 5-year-olds

Option 1 Option 2

33\% (6) 67\% (12)

$22 \%$ (4) $78 \%$ (14)

$11 \%$ (2) $\quad 89 \%$ (16) 